\title{
2'-Alkynylnucleotides: A Sequence- and Spin Label-Flexible Strategy for EPR Spectroscopy in DNA
}

\author{
Marius M. Haugland, ${ }^{\dagger}$ Afaf H. El-Sagheer, ${ }^{\dagger}, \mathbb{I}$ Rachel J. Porter, ${ }^{\dagger}$ Javier Peña, ${ }^{\ddagger}$ Tom Brown, ${ }^{*}{ }^{\dagger}$ \\ Edward A. Anderson, ${ }^{* \dagger}{ }^{\dagger}$ and Janet E. Lovett ${ }^{*}$, \\ ${ }^{\dagger}$ Department of Chemistry, Chemistry Research Laboratory, University of Oxford, Oxford, OX1 3TA, U.K. \\ ${ }^{\text {II } C h e m i s t r y ~ B r a n c h, ~ F a c u l t y ~ o f ~ P e t r o l e u m ~ a n d ~ M i n i n g ~ E n g i n e e r i n g, ~ S u e z ~ U n i v e r s i t y, ~ S u e z ~ 43721, ~ E g y p t ~}$ \\ ${ }^{\ddagger}$ Departamento de Química Orgánica, Universidad de Salamanca, Plaza de los Caídos 1-5, 37008 Salamanca, Spain \\ ${ }^{\S}$ SUPA, School of Physics and Astronomy, University of St Andrews, North Haugh, St Andrews, KY16 9SS, U.K.
}

Supporting Information

ABSTRACT: Electron paramagnetic resonance (EPR) spectroscopy is a powerful method to elucidate molecular structure through the measurement of distances between conformationally well-defined spin labels. Here we report a sequence-flexible approach to the synthesis of double spinlabeled DNA duplexes, where 2 '-alkynylnucleosides are incorporated at terminal and internal positions on complementary strands. Post-DNA synthesis coppercatalyzed azide-alkyne cycloaddition ( $\mathrm{CuAAC}$ ) reactions with a variety of spin labels enable the use of double electron-electron resonance experiments to measure a number of distances on the duplex, affording a high level of detailed structural information.

$\mathrm{T}$ he development of selective and accurate methods for visualizing biomolecules is essential for understanding the relationship between structure and activity in biological systems. Electron paramagnetic resonance (EPR) spectroscopy is rapidly emerging as a powerful tool in this context. ${ }^{1}$ The pulsed EPR technique double electron-electron resonance (DEER) is particularly useful for applications to biopolymers, where the dipolar coupling between two paramagnetic centers enables the measurement of interspin distances of 15 to $>100 \AA$, as well as spin label orientations.

In biopolymers without natural paramagnetic centers (e.g., metal ions), spin labels must be introduced in a site-specific fashion. These should be conformationally restricted to maximize accuracy in EPR experiments, but equally should not perturb the structure or function of the biopolymer. A variety of strategies have been developed for the site-directed spin labeling (SDSL) of nucleic acids, ${ }^{3}$ including modification of the nucleobase, ${ }^{2 a, 4}$ phosphodiester, ${ }^{5}$ and ribose framework. ${ }^{6}$ For example, the cytidine analogue $\mathbf{C}$ (Figure 1) gives rigid oligonucleotide structures and detailed angular information, ${ }^{4 \mathrm{e}, \mathrm{f}}$ but inherently restricts sequence generality. $2^{\prime}$-(Thio)urea ${ }^{6 c-f}$ and propargyl ether-derived triazole ${ }^{6 \mathrm{~b}}$ linkers (1) achieve ribose labeling; despite greater sequence flexibility, the former requires hydrolytically sensitive labeling reagents (e.g., iso(thio)cyanates), while the latter are relatively mobile, which reduces the accuracy of distance measurements. Here we describe a new approach to oligonucleotide spin-labeling through the incorpo-
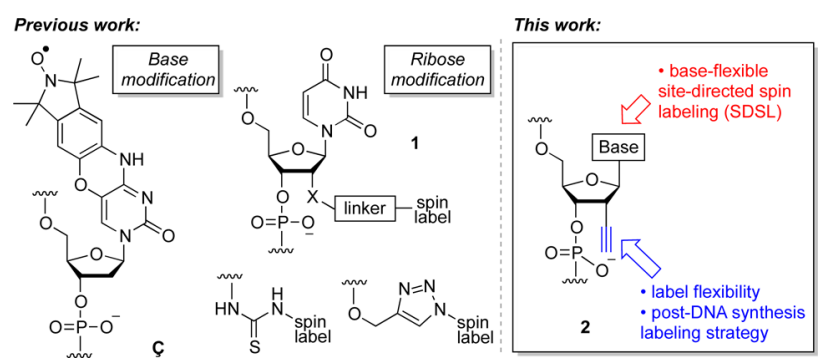

Figure 1. Examples of SDSL strategies: Cytidine analogue Ç, $2^{\prime}$-linked spin labels (1), and the $2^{\prime}$-ethynyl-2'-deoxynucleotide SDSL approach (2).

ration of 2'-alkynylnucleosides into DNA (2). As well as tolerating standard DNA synthesis conditions, this sequenceflexible approach enables post-DNA synthesis CuAAC click reactions to install a variety of spin labels. DEER experiments on double spin-labeled duplexes afford an array of distance measurements, which generate a detailed structural "map" of the duplex, and reveal the importance of spin label structure on distance distribution.

The synthesis of 2 -ethynyl-2'-deoxyuridine (3, Scheme 1 ) built on the elegant silicon-tethered radical alkyne transfer chemistry developed by Shuto et al. ${ }^{7}$ Starting with cyclouridine 4, protected 2 '-iodonucleoside 5 was obtained in two steps. Mild activation of aminosilane $\mathbf{6}$ with iodomethane greatly enhanced yields in the subsequent challenging silylation of the $3^{\prime}$-hydroxyl group of $5 .^{8}$ The resulting silyl ether 7 was immediately submitted to the radical atom transfer step, where the reported conditions ${ }^{7}$ ( 0.3 equiv of $\mathrm{BEt}_{3}$, toluene, $\mathrm{Ar}$ ) led to incomplete conversion and side reactions. However, the reaction proceeded smoothly when performed in benzene with trace amounts of air, which delivered 2 -alkynyluridine derivative 3 in high yield on multigram scale. Compound 3 was also converted to the $2^{\prime}$ alkynylcytidine derivative $\mathbf{8}$. $^{9}$

The preparation of $2^{\prime}$-ethynyl- $2^{\prime}$-deoxyadenosine 9 proved more challenging. This began with arabinoadenosine 10, which was converted to $2^{\prime}$-iodonucleoside $\mathbf{1 1}$ using a disiloxane protection strategy. After $N$-benzoylation, desilylation, and

Received: May 26, 2016

Published: July 13, 2016 
Scheme 1. Synthesis of $2^{\prime}$-Ethynyl-2' -deoxynucleoside Derivatives

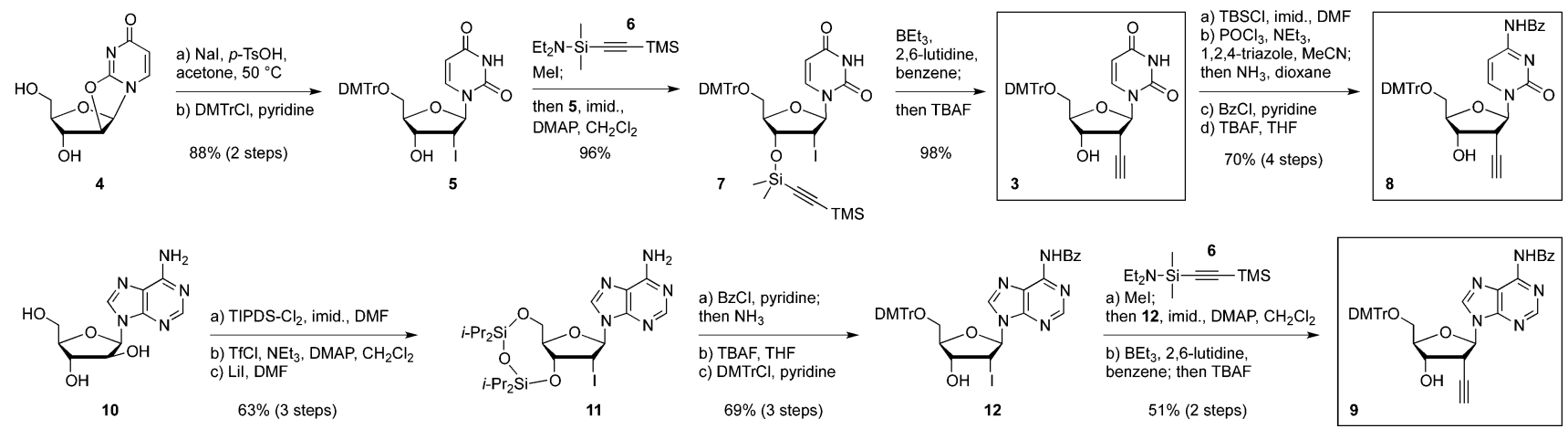

Scheme 2. Synthesis of Spin-Labeled DNA Duplexes

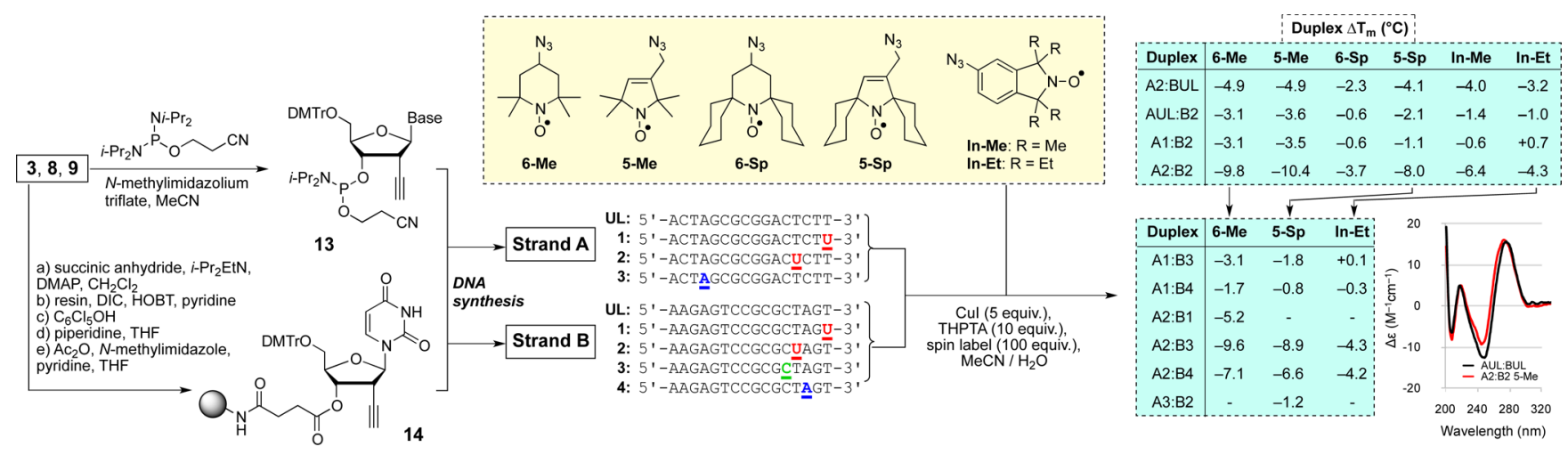

tritylation of the $5^{\prime}$-hydroxyl, equivalent chemistry used in the synthesis of $\mathbf{3}$ was deployed. The alkynylsilyl ether derived from 12 was less stable than uridine analogue 7 and was submitted to the radical atom transfer without chromatographic purification, which gave 9 in reasonable yield.

The 2'-alkynylnucleoside derivatives 3,8 , and 9 were converted to the corresponding $3^{\prime}$-O-(cyanoethyl)phosphoramidites $\mathbf{1 3}$ for incorporation into internal positions of DNA oligonucleotides (Scheme 2). Additionally, 3 was resin-mounted via succinylation of the $3^{\prime}$-alcohol (14), thereby enabling modification of the $3^{\prime}$-terminus of the DNA. These building blocks were successfully incorporated into two complementary single stranded DNA oligonucleotides using automated solidphase synthesis, at both terminal and internal positions (Strands A1-3 and B1-4, Scheme 2; unlabeled strands AUL and BUL were also prepared). To our knowledge, this is the first time a $2^{\prime}$ alkyne modification has been incorporated into DNA. The versatility of this approach is emphasized by the incorporation of the modified nucleotide at three adjacent (different) bases on Strand B.

The divergent nature of the strategy facilitates the exploration of the properties of different spin labels. For this we identified a small library of six azidonitroxides (see box, Scheme 2), which would be incorporated into the modified oligonucleotides postDNA synthesis. ${ }^{10}$ These spin labels were selected to explore the competing requirements of label/duplex rigidity and minimized structural distortion, including labels that display improved biological stability and/or spectroscopic properties. The wellestablished 6-Me and 5-Me enable evaluation of our strategy against other methods, with 5-Me known to be more resistant to bioreduction. ${ }^{11}$ Rotation of the methyl groups in these nitroxides provides a mechanism for relaxation of excited electron spins; this can be avoided through the use of the rigidified bis(spirocyclohexyl) spin labels 6-Sp and 5-Sp, where longer phase memory times $\left(T_{2 \mathrm{~m}}\right)$ enable DEER measurements to be performed at higher temperatures. ${ }^{4 \mathrm{~b}, 12}$ Tetraalkylisoindoline spin labels such as In-Me and In-Et are also of interest due to their enhanced rigidity, combined with high stability toward reducing environments. ${ }^{6 f, 13}$

These spin labels were site-selectively attached to the modified DNA via CuAAC chemistry. ${ }^{14}$ Due to the intolerance of some of these nitroxyls to sodium ascorbate, modified reaction conditions were used (copper(I) iodide/tris(3-hydroxypropyltriazolylmethyl) amine). Duplexes with various combinations of A and B strands were formed, and the consequence of introducing the spin label at the 2 '-position was investigated through UV denaturation studies and CD spectroscopy. ${ }^{13}$ We first examined the structural influence of a single internal label (A2:BUL and AUL:B2) on the DNA duplex melting temperature $\left(T_{\mathrm{m}}\right) .^{16}$ Internal labeling of Strand B was consistently found to be less destabilizing, with a moderate (up to $4{ }^{\circ} \mathrm{C}$ ) dependence on the spin label identity. Little or no change from these values was seen in double spin-labeled duplexes with terminal and internal labels (e.g., A1:B2). However, double-internal spin labeling had a more significant effect and also showed the greatest variance of $T_{\mathrm{m}}$ with spin label (up to $6.7^{\circ} \mathrm{C}$ ), although there appeared to be little correlation with the size of the label. For example, A2:B2-6-Sp showed the lowest $T_{\mathrm{m}}$ depression; this may be due to hydrophobic stacking interactions, possibly with the sugar to its $3^{\prime}$-side. CD spectroscopy confirmed that the B-form DNA helix is conserved, even in the most destabilized duplex (Scheme 2, CD spectra of AUL:BUL and A2:B2-5-Me). ${ }^{10}$

Room temperature continuous wave (CW) EPR was carried out using single-labeled duplexes. ${ }^{10}$ The A1:BUL duplexes showed greater label mobility than A2:BUL or AUL:B2, which is consistent with labeling of a terminal nucleotide in A1:BUL. 

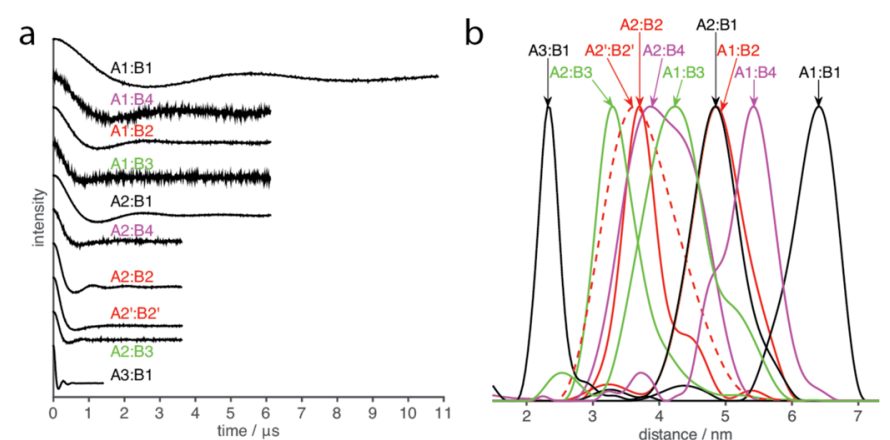

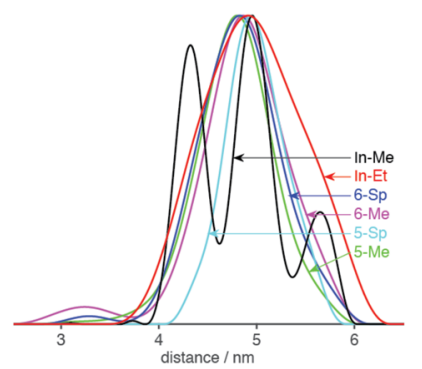

d

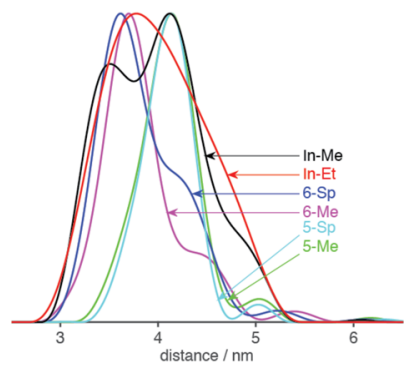

Figure 2. DEER data for the spin labeled duplexes. (a) DEER time traces for the series of 6-Me labeled duplexes. A3 is 5-Sp labeled and A2':B2' denotes a $2^{\prime}$-triazolylmethyl ether tether (see text). (b) Distance distributions derived from DEER using DeerAnalysis $2015^{17}$ for the data series shown in a. (c) Distance distributions for A1:B2 duplexes. (d) Distance distributions for A2:B2 duplexes.

Interestingly, marked differences in mobility were observed between different labels in all duplexes, with 6-Me and 5-Me exhibiting the most rapid dynamics. The $T_{1}$ relaxation time and $T_{2 \mathrm{~m}}$ were next determined for the various labels in A1:BUL. ${ }^{10}$ Labels with flanking tetramethyl or tetraethyl substituents generally exhibit a pronounced turning point in their relaxation rates as the rotation of the alkyl groups becomes less dominant in the relaxation process; ${ }^{12 a}$ in our duplexes, this was only observed for In-Et, which could indicate that local environment is an important factor for this effect. ${ }^{10,12 \mathrm{c}}$ The 6-Sp and 5-Sp labels were observed to have a much longer $T_{2 \mathrm{~m}}$ at all temperatures. ${ }^{12}$

Pulsed EPR techniques were used to measure distances between spin labels in double-labeled duplexes. The backgroundcorrected DEER time traces for the 6-Me-labeled duplexes typically showed one or two frequency modulations (Figure 2a), suggesting that the labels occupy a relatively narrow region of conformational space.

The DEER-derived distance distributions obtained for this series of duplexes (Figure 2b) show that the average hwhh of 0.45 $\pm 0.13 \mathrm{~nm}$ is broadly independent of the influence of the label on the $T_{\mathrm{m}}$ of the duplex, and whether the label is placed internally or at the $3^{\prime}$ end of the duplex (in contrast to the measured mobilities at rt). Pleasingly, similar distance measurements were observed for the pseudosymmetric A1:B2 (red curve) and A2:B1 (black curve) duplexes, which supports well-defined positioning of the labels. An exception was the double internal labeled A2:B4, which gave a broader distribution; however, this illustrates the value of positioning spin labels at will to improve accuracy in the exploration of duplex structure. The red dashed curve in Figure $2 \mathrm{~b}$ depicts 6-Me attached via a 2'-O-propargyl ether-clicked triazole in the double internal labeled $\mathrm{A} 2^{\prime}: \mathrm{B} 2^{\prime}$. The hwhh increased to $0.65 \mathrm{~nm}$, reflecting the increased mobility associated with this more flexible linker, compared to $0.29 \mathrm{~nm}$ for A2:B2-6Me. $^{6 \mathrm{~b}}$ Similar results were obtained using 5-Sp and In-Et labels with this linker. ${ }^{10}$ For duplexes with interspin distances at which DEER is less accurate $(<1.5 \mathrm{~nm}),{ }^{2 \mathrm{e}}$ line-broadening of the frozen CW EPR spectra was used to approximate distances using $\mathbf{5 - S p}$ as the spin label; this gave values for $\mathrm{A} 3: \mathrm{B} 2, \mathrm{~A} 3: \mathrm{B} 3$, and $\mathrm{A} 3: \mathrm{B} 4$ $(0.9,1.0$, and $1.3 \mathrm{~nm}$, respectively).

The DEER distance measurement, and hence label environment, was found to depend on the structure of the spin label. For example, measurements on the various A1:B2 duplexes (Figure 2c) afforded similar distances, with $\mathbf{5 - S p}$ giving the narrowest distribution. Interestingly, the distance distribution for In-Me showed three well-resolved maxima (Figure 2c, black curve), which suggest three distinct conformations of the pairs of labels. The double-internal A2:B2 duplexes (Figure 2d) replicate this phenomenon: the most probable distances (and conformations) clearly depend on label type. The conformational preferences correlate with the nature of the nitroxyl-containing ring: 5membered rings $5-\mathrm{Me}$ and $\mathbf{5 - S p}$ are positioned at $\sim 4.2 \mathrm{~nm}$ separation, while 6-membered rings 6-Me and 6-Sp are at $\sim 3.6$ $\mathrm{nm}$. It is also notable that the width of the distributions appear unrelated to the dynamics of the labels observed in the rt CW EPR experiments: for example, the distributions for A2:B2-5Me and -5-Sp overlap completely, although the dynamics are different. ${ }^{18}$ The broadest distributions were consistently obtained for In-Et, despite the slow dynamics exhibited in the CW EPR; this may imply that this sterically encumbered spin label associates with the duplex in a less well-defined manner than other labels.

A representation of the B-form helical DNA of the unlabeled duplex AUL:BUL is illustrated in Figure 3. The most probable

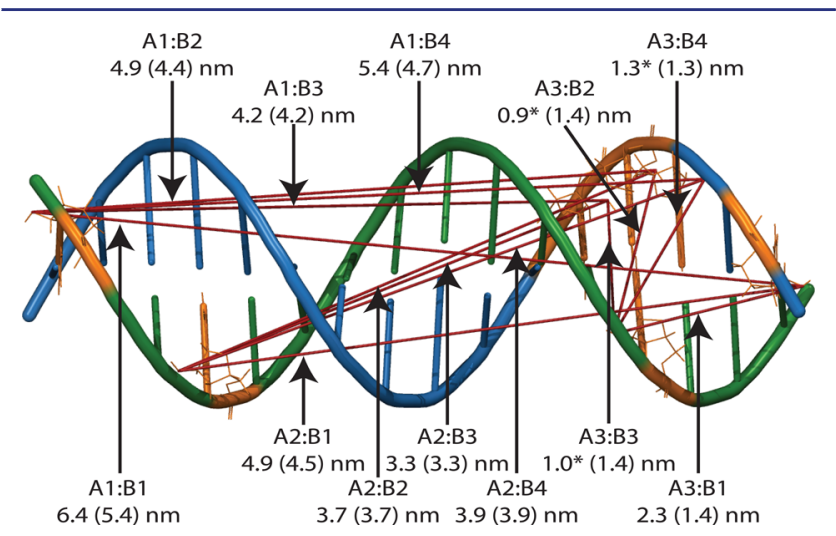

Figure 3. Representation of the B-form helical DNA (Maestro 10.5, Schrödinger, LLC). The A-strand backbone is shown in green and the Bstrand in blue. Labeled positions are represented in orange. Modal distances from DEER distance measurements (see Figure 2) and powder CW EPR spectra (denoted *) are shown. Distances in brackets were measured between the $2^{\prime}$-hydroxyl $\mathrm{O}$ atoms of the model (Pymol 1.4, Schrödinger, LLC).

distances from the DEER experiments and the approximate distances from CW EPR are shown, with calculated distances between the 2 '-hydroxyls in a B-form mixed DNA/RNA model duplex depicted for comparison. ${ }^{19}$ Good correlation is found between these modeled distances and the measured interspin distances, particularly for internal labels (mean deviation -0.01 $\pm 0.06 \mathrm{~nm}$ for DEER measurements). Notably, the measured $\mathrm{A} 3: \mathrm{B} 4$ distance $(1.30 \mathrm{~nm})$ is significantly greater than $\mathrm{A} 3: \mathrm{B} 2$ or A3:B3 $(\sim 1.0 \mathrm{~nm})$, despite similar calculated $2^{\prime}-\mathrm{OH}-2^{\prime}-\mathrm{OH}$ 
distances. This may imply that the spin labels are oriented toward the $3^{\prime}$ terminus in a directionally well-defined manner, rather than projecting into solution. ${ }^{6 \mathrm{~d}, \mathrm{f}}$ The duplexes labeled at the $3^{\prime}$ termini consistently afford distances greater than the crude model (mean deviation $0.49 \pm 0.31 \mathrm{~nm}$ for 6-Me labeled duplexes). The hwh of these distributions suggests that the labels nonetheless adopt well-defined conformations.

In conclusion, we have developed a sequence-flexible method for oligonucleotide spin labeling. 2'-Alkynylnucleosides were incorporated into a 16-mer DNA duplex at various positions using standard solid phase synthesis and were functionalized with a range of azide-containing nitroxides. Pulsed and CW EPR experiments were used to determine dynamic and electron spin relaxation properties of the labels and to measure interspin distances, with the structure of the radical probe influencing the positioning of the spin label on the duplex. The structural information obtained demonstrates the versatility of this approach in exploring the structure of nucleic acids, including applications beyond SDSL.

\section{ASSOCIATED CONTENT}

\section{S Supporting Information}

The Supporting Information is available free of charge on the ACS Publications website at DOI: 10.1021/jacs.6b05421.

Experimental conditions, characterization of oligonucleotides and EPR data (PDF)

Copies of NMR data (PDF)

\section{AUTHOR INFORMATION}

\section{Corresponding Authors}

*tom.brown@chem.ox.ac.uk

*edward.anderson@chem.ox.ac.uk

*jel20@st-andrews.ac.uk

\section{Notes}

The authors declare no competing financial interest.

\section{ACKNOWLEDGMENTS}

TB and AHE-S thank the BBSRC (sLOLA grant BB/J001694/ 1). EAA thanks the EPSRC (EP/K005391/1, EP/M019195/1). JEL thanks the EPSRC (EP/LO22044/1), and the Royal Society for a University Research Fellowship and grant RF120645. We thank the Wellcome Trust for the Q-band EPR spectrometer (099149/Z/12/Z), the EPSRC National EPR Service for spectrometer time, and Dr Hassane El Mkami for technical assistance.

\section{REFERENCES}

(1) (a) Klare, J. P.; Steinhoff, H. J. Photosynth. Res. 2009, 102, 377. (b) Ward, R.; Schiemann, O. Struct. Bonding (Berlin, Ger.) 2012, 152, 249.

(2) (a) Halbmair, K.; Seikowski, J.; Tkach, I.; Höbartner, C.; Sezer, D.; Bennati, M. Chem. Sci. 2016, 7, 3172. (b) Endeward, B.; Marko, A.; Denysenkov, V. P.; Sigurdsson, S. T.; Prisner, T. F. Methods Enzymol. 2015, 564, 403. (c) El Mkami, H.; Norman, D. G. Methods Enzymol. 2015, 564, 125. (d) Borbat, P. P.; Freed, J. H. Struct. Bonding (Berlin, Ger.) 2013, 152, 1. (e) Banham, J. E.; Baker, C. M.; Ceola, S.; Day, I. J.; Grant, G. H.; Groenen, E. J. J.; Rodgers, C. T.; Jeschke, G.; Timmel, C. R. J. Magn. Reson. 2008, 191, 202. (f) Lovett, J. E.; Bowen, A. M.; Timmel, C. R.; Jones, M. W.; Dilworth, J. R.; Caprotti, D.; Bell, S. G.; Wong, L. L.; Harmer, J. Phys. Chem. Chem. Phys. 2009, 11, 6840.

(3) Shelke, S. A.; Sigurdsson, S. T. Nucleic Acids Mol. Biol. 2016, 31, 159.
(4) (a) Duss, O.; Yulikov, M.; Jeschke, G.; Allain, F. H. T. Nat. Commun. 2014, 5, 3669. (b) Babaylova, E. S.; Ivanov, A. V.; Malygin, A. A.; Vorobjeva, M. A.; Venyaminova, A. G.; Polienko, Y. F.; Kirilyuk, I. A.; Krumkacheva, O. A.; Fedin, M. V.; Karpova, G. G.; Bagryanskaya, E. G. Org. Biomol. Chem. 2014, 12, 3129. (c) Ding, P.; Wunnicke, D.; Steinhoff, H. J.; Seela, F. Chem. - Eur. J. 2010, 16, 14385. (d) Sicoli, G.; Wachowius, F.; Bennati, M.; Höbartner, C. Angew. Chem., Int. Ed. 2010, 49, 6443. (e) Schiemann, O.; Cekan, P.; Margraf, D.; Prisner, T. F.; Sigurdsson, S. T. Angew. Chem., Int. Ed. 2009, 48, 3292. (f) Barhate, N.; Cekan, P.; Massey, A. P.; Sigurdsson, S. T. Angew. Chem., Int. Ed. 2007, 46, 2655. (g) Schiemann, O.; Piton, N.; Plackmeyer, J.; Bode, B. E.; Prisner, T. F.; Engels, J. W. Nat. Protoc. 2007, 2, 904.

(5) (a) Popova, A. M.; Kálai, T.; Hideg, K.; Qin, P. Z. Biochemistry 2009, 48, 8540. (b) Cai, Q.; Kusnetzow, A. K.; Hubbell, W. L.; Haworth, I. S.; Gacho, G. P. C.; Van Eps, N.; Hideg, K.; Chambers, E. J.; Qin, P. Z. Nucleic Acids Res. 2006, 34, 4722. (c) Nguyen, P. H.; Popova, A. M.; Hideg, K.; Qin, P. Z. BMC Biophys. 2015, 8, 6.

(6) (a) Shevelev, G. Y.; Krumkacheva, O. A.; Lomzov, A. A.; Kuzhelev, A. A.; Rogozhnikova, O. Y.; Trukhin, D. V.; Troitskaya, T. I.; Tormyshev, V. M.; Fedin, M. V.; Pyshnyi, D. V.; Bagryanskaya, E. G. J. Am. Chem. Soc. 2014, 136, 9874. (b) Flaender, M.; Sicoli, G.; Fontecave, T.; Mathis, G.; Saint-Pierre, C.; Boulard, Y.; Gambarelli, S.; Gasparutto, D. Nucleic Acids Symp. Ser. 2008, 52, 147. (c) Edwards, T. E.; Okonogi, T. M.; Robinson, B. H.; Sigurdsson, S. T. J. Am. Chem. Soc. 2001, 123, 1527. (d) Ward, R.; Keeble, D. J.; El Mkami, H.; Norman, D. G. ChemBioChem 2007, 8, 1957. (e) Kim, N. K.; Bowman, M. K.; DeRose, V. J. J. Am. Chem. Soc. 2010, 132, 8882. (f) Saha, S.; Jagtap, A. P.; Sigurdsson, S. T. Chem. Commun. 2015, 51, 13142.

(7) (a) Sukeda, M.; Ichikawa, S.; Matsuda, A.; Shuto, S. Angew. Chem., Int. Ed. 2002, 41, 4748. (b) Sukeda, M.; Ichikawa, S.; Matsuda, A.; Shuto, S. J. Org. Chem. 2003, 68, 3465.

(8) Ohshita, J.; Iwata, A.; Kanetani, F.; Kunai, A.; Yamamoto, Y.; Matui, C. J. Org. Chem. 1999, 64, 8024.

(9) Divakar, K. J.; Reese, C. B. J. Chem. Soc., Perkin Trans. 1 1982, 1171.

(10) See the Supporting Information for details.

(11) Couet, W. R. R.; Brasch, R. C. C.; Sosnovsky, C.; Lukszo, J.; Prakash, I.; Gnewech, C. T. T.; Tozer, T. N. N. Tetrahedron 1985, 41, 1165.

(12) (a) Kathirvelu, V.; Smith, C.; Parks, C.; Mannan, M. A.; Miura, Y.; Takeshita, K.; Eaton, S. S.; Eaton, G. R. Chem. Commun. 2009, 454. (b) Kirilyuk, I. A.; Polienko, Y. F.; Krumkacheva, O. A.; Strizhakov, R. K.; Gatilov, Y. V.; Grigor'ev, I. A.; Bagryanskaya, E. G. J. Org. Chem. 2012, 77, 8016. (c) Kuzhelev, A. A.; Strizhakov, R. K.; Krumkacheva, O. A.; Polienko, Y. F.; Morozov, D. A.; Shevelev, G. Y.; Pyshnyi, D. V.; Kirilyuk, I. A.; Fedin, M. V.; Bagryanskaya, E. G. J. Magn. Reson. 2016, 266, 1.

(13) (a) Jagtap, A. P.; Krstic, I.; Kunjir, N. C.; Hänsel, R.; Prisner, T. F.; Sigurdsson, S. T. Free Radical Res. 2015, 49, 78. (b) Paletta, J. T.; Pink, M.; Foley, B.; Rajca, S.; Rajca, A. Org. Lett. 2012, 14, 5322.

(14) (a) El-Sagheer, A. H.; Brown, T. Chem. Soc. Rev. 2010, 39, 1388. (b) Amblard, F.; Cho, J. H.; Schinazi, R. F. Chem. Rev. 2009, 109, 4207.

(15) (a) 2'-Triazoles derived from 2'-azidonucleotides are welltolerated in nucleic acids. See: Fauster, K.; Hartl, M.; Santner, T.; Aigner, M.; Kreutz, C.; Bister, K.; Ennifar, E.; Micura, R. ACS Chem. Biol. 2012, 7, 581. (b) Sau, S. P.; Hrdlicka, P. J. J. Org. Chem. 2012, 77, 5.

(16) The duplex AUL:BUL displayed a $T_{\mathrm{m}}$ value of $68.1^{\circ} \mathrm{C}$. The typical error (standard deviation) in $T_{\mathrm{m}}$ measurement is $\pm 0.3-0.5^{\circ} \mathrm{C}$. See the Supporting Information.

(17) Jeschke, G.; Chechik, V.; Ionita, P.; Godt, A.; Zimmermann, H.; Banham, J.; Timmel, C. R.; Hilger, D.; Jung, H. Appl. Magn. Reson. 2006, 30, 473.

(18) The differences between label types were further compared through labeling the A1, A2, and B2, B3, B4 duplexes with 6-Me, 5-Sp, and In-Et; see the Supporting Information.

(19) More accurate interpretation of the positioning and orientation of the different spin labels through modeling and/or X-ray crystallographic studies will be reported in due course. 